\title{
Specific control of BMP signaling and mesenchymal differentiation by cytoplasmic phosphatase PPM1H
}

\author{
Tao Shen ${ }^{2,3,4}$, Chuang Sun ${ }^{2,5}$, Zhengmao Zhang ${ }^{2}$, Ningyi Xu' ${ }^{1}$, Xueyan Duan ${ }^{3}$, Xin-Hua Feng ${ }^{1,2,3,5}$, Xia Lin ${ }^{2}$ \\ ${ }^{1}$ Life Sciences Institute, Zhejiang University, Hangzhou, Zhejiang 310058, China; ${ }^{2}$ Michael E DeBakey Department of Surgery, \\ Baylor College of Medicine, Houston, TX 77030, USA; ${ }^{3}$ Department of Molecular \& Cellular Biology, Baylor College of Medicine, \\ Houston, TX 77030, USA; ${ }^{4}$ Institute of Biosciences and Technology, Texas A\&M University Health Science Center, Houston, TX \\ 77030, USA; ${ }^{5}$ Department of Molecular Physiology and Biophysics, Baylor College of Medicine, Houston, TX 77030, USA
}

Bone morphogenetic proteins (BMPs) belong to the TGF- $\beta$ superfamily of structurally related signaling proteins that regulate a wide array of cellular functions. The key step in BMP signal transduction is the BMP receptormediated phosphorylation of transcription factors Smad1, 5, and 8 (collectively Smad1/5/8), which leads to the subsequent activation of BMP-induced gene transcription in the nucleus. In this study, we describe the identification and characterization of PPM1H as a novel cytoplasm-localized Smad1/5/8-specific phosphatase. PPM1H directly interacts with Smad1/5/8 through its Smad-binding domain, and dephosphorylates phospho-Smad1/5/8 (P-Smad1/5/8) in the cytoplasm. Ectopic expression of PPM1H attenuates BMP signaling, whereas loss of PPM1H activity or expression greatly enhances BMP-dependent gene regulation and mesenchymal differentiation. In conclusion, this study suggests that PPM1H acts as a gatekeeper to prevent excessive BMP signaling through dephosphorylation and subsequent nuclear exclusion of P-Smad1/5/8 proteins.

Keywords: phosphorylation; protein phosphatases; signal transduction; TGF- $\beta$

Cell Research (2014) 24:727-741. doi:10.1038/cr.2014.48; published online 15 April 2014

\section{Introduction}

Bone morphogenetic proteins (BMPs) are a group of growth factors and cytokines originally identified by their ability to induce the formation of bone and cartilage in vivo $[1,2]$. With the exception of BMP1, BMPs belong to the transforming growth factor- $\beta$ (TGF- $\beta$ ) superfamily [3]. Genetic studies have demonstrated that BMPs play important roles in skeletal development, including osteoblast expansion, differentiation, and bone formation [4]. In addition to their functions in skeletal development, BMPs are critical signaling molecules in early embryo development and organogenesis by regulating cell prolif-

Correspondence: Xin-Hua Feng ${ }^{\mathrm{a}}$, Xia Lin ${ }^{\mathrm{b}}$

${ }^{\mathrm{a}}$ Tel: +1-713-7984756

E-mail: xfeng@bcm.edu

${ }^{\mathrm{b}}$ Tel: +1-713-7984899

E-mail: xialin@bcm.edu

Received 31 October 2013; revised 19 February 2014; accepted 26 February

2014; published online 15 April 2014 eration, differentiation, migration, and apoptosis [5-10]. Abrogation of BMP signaling is associated with skeletal, cardiovascular and autoimmune diseases, and cancer [1117].

BMP signaling is initiated by the binding of ligands to the BMP receptor complex consisting of type I and type II receptors at the cell surface [18]. Depending on the identity of the ligands, various combinations of four distinct type I receptors (activin receptor-like kinase ALK-1/2/3/6) with three type II receptors (BMPRII, ActRIIA, or ActRIIB) are involved [19]. Activated BMP type I receptor phosphorylates intracellular mediators of BMP signaling, Smad1/5/8, which in turn form an oligomeric complex with Smad4. The Smad complex translocates into the nucleus, binds to the consensus DNA sequence, and recruits distinct transcriptional cofactors to regulate transcription of BMP target genes $[7,8$, 20]. For example, BMPs induce transcriptional activation of the inhibitor of DNA binding (Id) genes in a Smaddependent manner [21].

In eukaryotic organisms, signal transduction pathways 
are often regulated by the dynamic interplay between protein kinases and phosphatases. Phosphorylation of Smad $1 / 5 / 8$ at the C-terminal SXS motif by BMP type $\mathrm{I}$ receptor is one of the most critical events in BMP signaling [22]. Protein phosphatases are anticipated to dephosphorylate phospho-Smad1/5/8 (P-Smad1/5/8) and consequently prevent or terminate BMP signaling. Several protein phosphatases have been reported to dephosphorylate Smads in the BMP/TGF- $\beta$ signal transduction pathways [22]. For example, PPM1A is a general R-Smad phosphatase that dephosphorylates both Smad2/3 [23] and Smad1/5/8 [24] at their C-terminal SXS motifs. PPM1A is localized predominantly in the nucleus [23]. MTMR4, an endosomal phosphatase, can also dephosphorylate all R-Smads [25]. In addition, Smad $1 / 5 / 8$ are also inactivated by $\underline{\text { small }} \underline{\mathrm{C}}$-terminal protein phosphatases SCP1/2/3 [26] in the nucleus. Intriguingly, a mitochondrial phosphatase PDP also dephosphorylates P-Smad1, but its mechanism remains elusive [27].

In the present study, we searched for specific phosphatases that target Smads in the BMP signaling. To this end, we have identified PPM1H (protein phosphatase magnesium-dependent $1 \mathrm{H}$ ), a PPM family member of protein serine/threonine phosphatases, as a novel phosphatase that dephosphorylates BMPspecific Smads. It has been previously suggested that PPM1H regulates neuronal signaling pathways [28], dephosphorylates CSE1L in colon adenocarcinoma [29] and dephosphorylates p27 in breast cancer [30]. However, the subcellular localization and precise physiological functions of PPM1H are still unclear. Here we describe a novel function of PPM1H in modulating BMP signaling through its physical interaction with and dephosphorylation of BMP-activated Smad proteins.

\section{Results}

\section{PPM1H dephosphorylates P-Smad1 in vivo and in vitro}

In our search for protein phosphatases targeting Smad, we performed genome-wide functional screens of all the protein serine/threonine phosphatases (PS/TP) encoded by the human genome. The initial screen identified nuclear PPM1A as a general R-Smad phosphatase that can dephosphorylate P-Smad2/3 [23] and P-Smad1/5/8 [24]. In a more exhaustive screen using P-Smad 1 as a substrate (for list of phosphatases, see Table 1), we identified PPM1H as a potential Smad1 phosphatase. This PPM1H activity was further confirmed by using a series of biochemical assays. As shown in Figure $1 \mathrm{~A}$, a constitutively active mutant of BMP receptor ALK3 (ALK3QD) induced Smad1 phosphorylation in
HEK293T cells (indicated by the P-Smad1 level) (lane 2). Co-expression of PPM1H attenuated P-Smad1 level in a dose-dependent manner (Figure 1A, lanes 3-5). However, PPM1H had no effect on the phosphorylation of Smad 2 induced by the constitutively active mutant of TGF- $\beta$ type I receptor (T202D) (Figure 1B, lanes 3-5), indicating that $\mathrm{PPM} 1 \mathrm{H}$ activity was specific towards the BMP-activated Smads, but not the TGF- $\beta$-activated Smads.

The effect of PPM1H on Smad1 phosphorylation was further confirmed in BMP-responsive mouse mesenchymal progenitor $\mathrm{C} 2 \mathrm{C} 12$ cells. We first generated $\mathrm{C} 2 \mathrm{C} 12$ cells stably expressing PPM1H at a level comparable to that of endogenous PPM1H or harboring control vector, and BMP2-induced Smad1 phosphorylation was examined in these two stable cell lines. As shown in Figure 1C, BMP2-induced Smad1 phosphorylation was markedly reduced in PPM1H-expressing cells when compared to that in control $\mathrm{C} 2 \mathrm{C} 12$ cells. In contrast, co-expression of PPM1H had no effect on the phosphorylation of Smad2 (indicated by the P-Smad2 level) in response to TGF- $\beta$ treatment in the same stable cell lines (Figure 1D). Immunofluorescence staining of P-Smad1 also confirmed that the level of nuclear Smad1 (indicative of P-Smad1 level) was significantly reduced in PPM1H-expressing cells (Figure 1E). The effect of PPM1H on Smad1 phosphorylation requires the phosphatase activity of $\mathrm{PPM} 1 \mathrm{H}$ as the catalytically inactive mutant of PPM1H, D437N (an Asp-to-Asn substitution at amino acid 437 in the catalytic loop of PPM1H), failed to inhibit the BMP2-induced Smad1 phosphorylation (Figure 1F, lanes 5-6).

Cell-based transfection assays suggested that PPM1H is a Smad1-specific phosphatase. To rule out the possibility that $\mathrm{PPM} 1 \mathrm{H}$ acts indirectly by activating another cellular phosphatase in cells that in turn directly dephosphorylates P-Smad1, we carried out an in vitro cell-free PPM1H phosphatase activity assay to determine whether PPM1H directly dephosphorylates P-Smad1. In this assay, recombinant GST-PPM1H fusion protein purified from bacteria was used as the phosphatase, while P-Smad1 immunoprecipitated from cells served as the substrate. P-Smad2 was also immunoprecipitated from cells and served as substrate specificity control. As shown in Figure 1G, PPM1H could efficiently dephosphorylate P-Smad1 in the in vitro phosphatase reaction buffer. PPM1H phosphatase activity was dependent on the presence of $\mathrm{Mg}^{2+}$, as expected for the PPM subfamily of phosphatases. In contrast, PPM1H had no effect on the dephosphorylation of P-Smad2 (Figure 1H) and the linker S206 site of P-Smad1 (Figure 1I), whereas it efficiently dephosphorylated the SXS motif 
Table 1 PS/TPs screening for Smad1 SXS-specific dephosphorylation

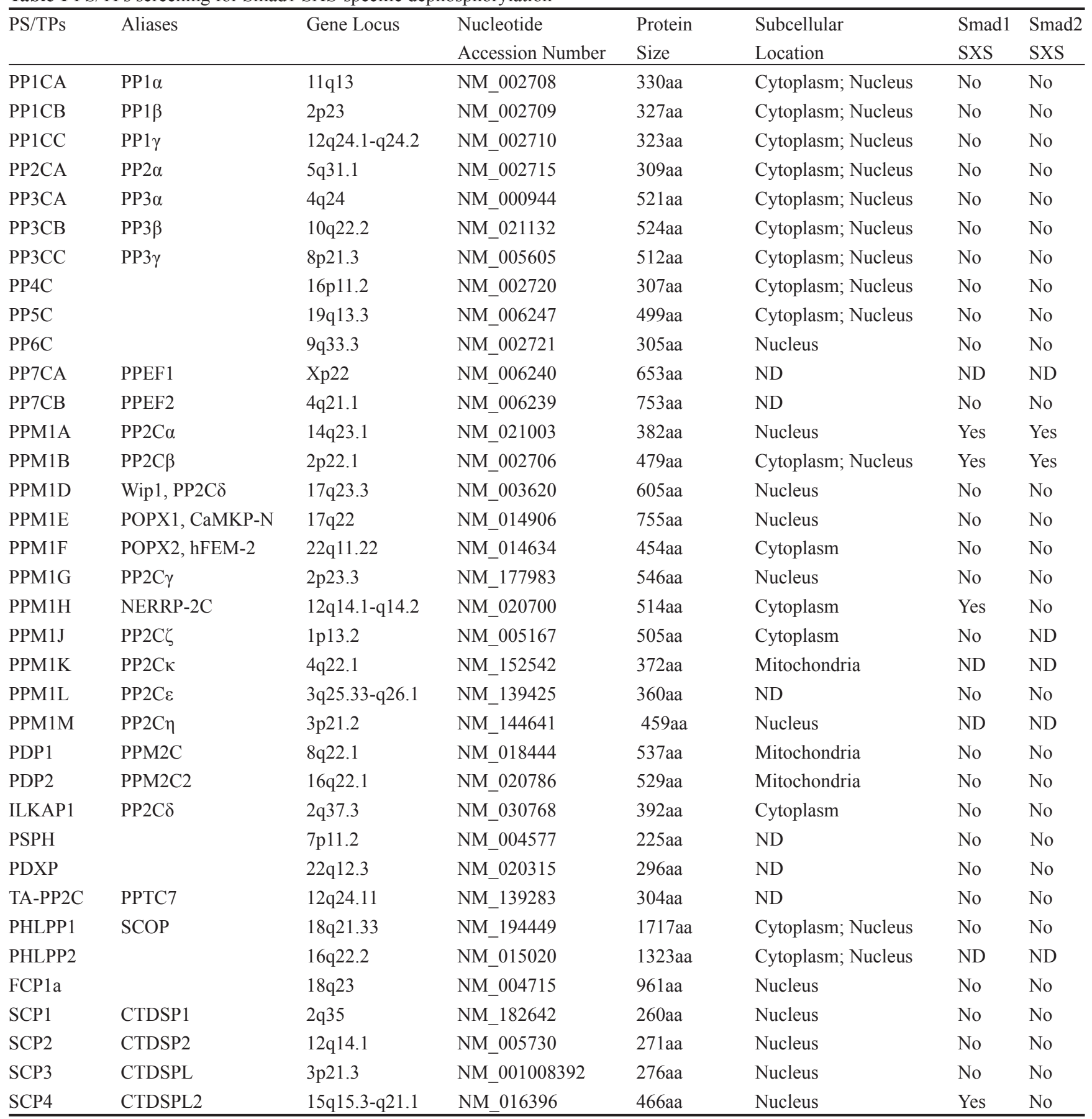

Note: Yes, detectable dephosphorylation; No, undetectable dephosphorylation; ND, not determined. SXS represents C-terminal SXS motif of Smad1 and Smad2, respectively.

of Smad1 (Figure 1I), suggesting that PPM1H directly dephosphorylates P-Smad1 at the C-terminal SXS motif, but does not dephosphorylate P-Smad2. Taken together, these results indicate that PPM1H is a BMP familyspecific Smad phosphatase.
PPM1H physically interacts with Smad1/5 through its $N$ terminal domain

The enzyme-substrate relationship often involves a physical interaction between them. To test whether PPM1H binds to Smad1/5, we performed in vivo co- 
A

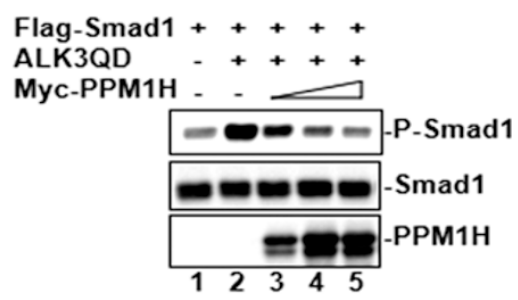

C



E

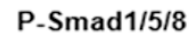

PPM1H

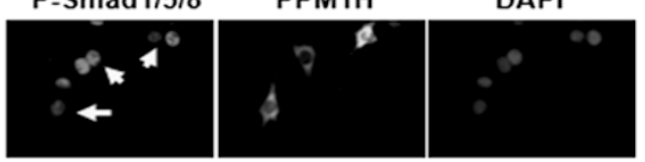

B



D



F

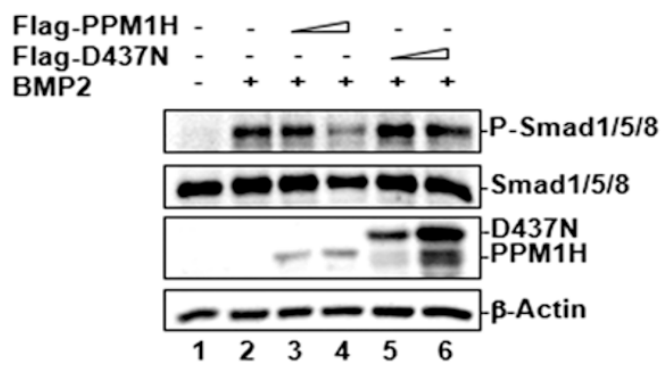

I

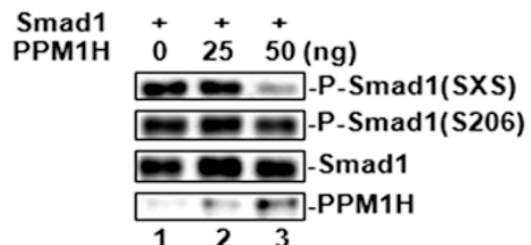

Figure 1 PPM1H dephosphorylates P-Smad1 in vivo and in vitro. (A) PPM1H dephosphorylates P-Smad1. HEK293 cells were transfected with Flag-Smad1 and an increasing amount of Myc-PPM1H. To stimulate Smad1 phosphorylation, constitutively active BMP type I receptor ALK3 (ALK3QD) was co-transfected. Levels of P-Smad1, total Smad1, and PPM1H were determined by western blotting. (B) PPM1H does not dephosphorylate Smad2. Experiment was carried out as described in A, with the exception that Flag-Smad2 and constitutively active TGF- $\beta$ type I receptor T202D were used. (C) Ligandinduced Smad1 phosphorylation is abolished in C2C12 cells stably expressing PPM1H. Cells were treated with BMP2 (5 ng/ml) for the indicated times, lysed, and P-Smad1 level was determined by western blotting. (D) PPM1H has no effect on ligand-induced Smad2 phosphorylation in C2C12 cells stably expressing PPM1H. Cells were treated with TGF- $\beta$ ( 2 ng/ml) for the indicated times, lysed, and P-Smad2 level was determined by western blotting. (E) PPM1H reduces endogenous P-Smad1 level. C2C12 cells were transfected with Myc-PPM1H, treated with BMP2 $(5 \mathrm{ng} / \mathrm{ml})$, and immunostained with anti-Myc and anti-P-Smad1 antibodies. The arrow indicates reduced P-Smad1 level in PPM1H-expressing cells. (F) Catalytically inactive mutant of PPM1H (D437N) fails to dephosphorylate Smad1. C2C12 cells were transfected with Flag-PPM1H or Flag-D437N, treated with BMP2 (5 ng/ $\mathrm{ml}$ ), and P-Smad1 level was determined by western blotting. (G) PPM1H directly dephosphorylates P-Smad1 in vitro. PPM1H was purified as GST fusion protein from bacteria, whereas P-Smad1 was purified by immunoprecipitation from cell lysates transfected with active BMP type I receptors. PPM1H was mixed with P-Smad1 in the phosphatase reaction buffer. Levels of P-Smad1 were determined by western blotting. (H) PPM1H does not dephosphorylate P-Smad2 in vitro. Experiment was done as in G. (I) PPM1H does not dephosphorylate phospho-S206 in the linker region of Smad1 in vitro. Experiment was done as in G. SXS indicates the canonical C-terminal phoshophorylation motif of Smad1. 
immunoprecipitation experiments in $\mathrm{C} 2 \mathrm{C} 12$ cells stably expressing Myc-tagged PPM1H. PPM1H was immunoprecipitated from cells by using anti-Myc antibody and the presence of endogenous Smad1 in the precipitates was determined by western blotting with anti-Smad1 antibody. Normal IgG was used as a non-specific negative control. We found that Smad1 co-precipitated with PPM1H (Figure 2A, lane 2), indicating that Smad1 and PPM1H form a complex in cells. Furthermore, we observed an interaction between endogenous PPM1H and Smad1/5 in C2C12 cells (Figure 2B) and HaCaT cells (data not shown), indicating that PPM1H interacts with Smad1/5 under the physiological conditions.

To identify the structural features that determine the PPM1H-Smad1/5 interaction, we mapped the interacting domains in both proteins. To determine which PPM1H regions bind to Smad1, we co-transfected HEK293T cells with Smad1 and full-length PPM1H, PPM1H N-terminal fragment (aa 1-200; PPM1H-N), or C-terminal fragment (aa 201-514, which contains the phosphatase catalytic domain; PPM1H-C). The ability of PPM1H to co-precipitate with Smad1 was examined by immunoprecipitation-coupled western blotting. As shown in Figure 2C, Smad1 was readily detected in immunoprecipitated PPM1H-N complex (lane 7), but not in PPM1H-C immunocomplex (lane 8), suggesting that the $\mathrm{N}$ terminus of $\mathrm{PPM} 1 \mathrm{H}$ is responsible for Smad1 binding. Meanwhile, the PPM1H-binding domain on Smad1 was determined by direct in vitro binding assays. Recombinant GST fusion proteins of Smad1, or the MH1 domain, the MH2 domain, and the linker region of Smad1 were incubated with in vitro translated, ${ }^{35}$ S-labeled Flag-PPM1H, followed by SDS-PAGE and autoradiography. As shown in Figure 2D, Flag-PPM1H strongly interacted with the MH2 domain of Smad1, weakly with the MH1 domain, but not with the linker region of Smad1, indicating that the $\mathrm{MH} 2$ domain of Smad1 is the main binding site for PPM1H.

Since PPM1H could specifically dephosphorylate Smad1, but not Smad2, in vivo and in vitro, we examined whether there is an interaction between PPM1H and Smad2, which might define the substrate specificity of a phosphatase. As shown in Figure 2E, PPM1H-N strongly interacted with Smad1, but not with Smad2.

In response to BMP signals, Smad1 is phosphorylated and translocated from the cytoplasm to the nucleus. To determine the subcellular compartment where PPM1H and Smad1 interact in living cells, we used the bimolecular fluorescence complementation (BiFC) method [31]. In BiFC, the reporter protein (YFP) is split into two fragments, the $\mathrm{N}$-terminal (aa 1-154) and the C-terminal (aa 155-238) fragments. Each fragment is fused with one of the two interacting protein partners to be tested. Protein-protein interaction will bring the fluorescent fragments together, allowing the functional YFP to reform and emit a fluorescent signal, which can be visualized under the microscope. We constructed expression plasmids for PPM1H and Smad1 fused to N- and Cterminal fragment of YFP, respectively (VN-PPM1H and YC-Smad1), and transfected them in HEK293T cells. The fusion of PPM1H or Smad1 with YFP fragments did not affect the localization of these proteins or the ability of PPM1H to dephosphorylate P-Smad1 in cells (data not shown). YC-Smad1/VN-vector (Figure 2F) or VN-PPM1H/YC-vector pair (data not shown) did not yield fluorescence in cells. Notably, co-expression of VN-PPM1H and YC-Smad1 produced fluorescence which was only detected in the cytoplasm (Figure $2 \mathrm{~F}$ ), suggesting that the interaction between Smad1 and PPM1H occurs in the cytoplasm. Similarly, the phosphatase-inactive PPM1H mutant D437N interacted with Smad1 in the cytoplasm (Figure 2F).

Ectopic expression of PPM1H attenuates BMP signaling

BMP-induced phosphorylation of $\mathrm{Smad} 1 / 5 / 8$ in the cytoplasm, the subsequent complex formation between Smad1 and co-Smad Smad4, and their nuclear translocation are the most critical events in the BMP signal transduction pathway. Because PPM1H physically interacts with and dephosphorylates P-Smad1 in the cytoplasm, we anticipated that PPM1H would prevent the transduction of BMP signals to the nucleus. We first examined whether PPM1H could inhibit the formation of the Smad1-Smad4 complex in cells. HEK293T cells were transfected with Myc-Smad4 and FlagSmad1, in the presence of wild-type PPM1H or D437N mutant. ALK3QD was co-expressed to induce Smad1 phosphorylation and the complex formation between Smad1 and Smad4 (Figure 3A, lane 4). We found that the level of Smad1-bound Smad4 was decreased by co-expression of PPM1H (lane 5), but not by the coexpression of D437N mutant (lane 6). Consistently, the BMP-induced endogenous complex formation between Smad1 and Smad4 was also reduced in $\mathrm{C} 2 \mathrm{C} 12$ cells stably expressing PPM1H (Figure 3B, compare lanes 6 and 12), suggesting that PPM1H inhibited Smad1Smad4 association through dephosphorylating P-Smad1. We next investigated the effect of PPM1H on BMPinduced Smad1 nuclear translocation. C2C12 control cells and cells stably expressing wild-type PPM1H or D437N mutant were treated with BMP2 for 60 min and the protein level of Smad1 in the nuclear and cytosolic fraction of cells was determined by western blotting. 
A

\section{C2C12-PPM1H}

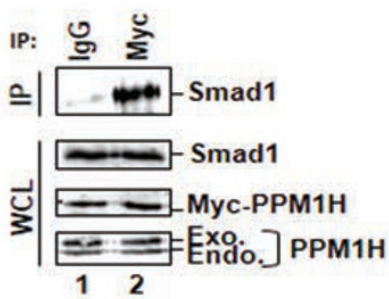

C

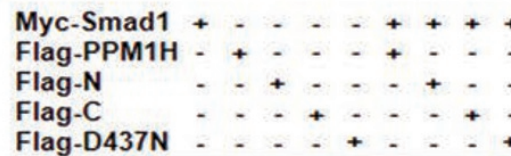

Flag-D437N - . . + . . +
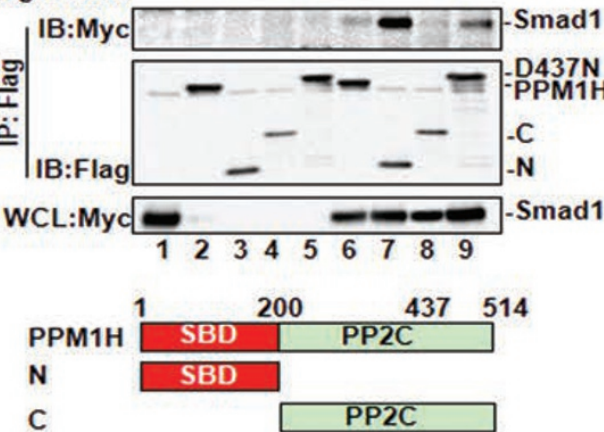

B

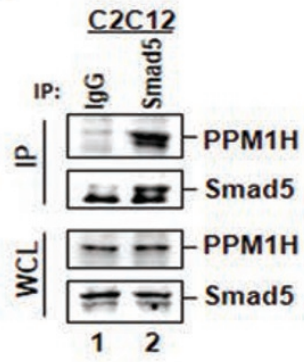

D
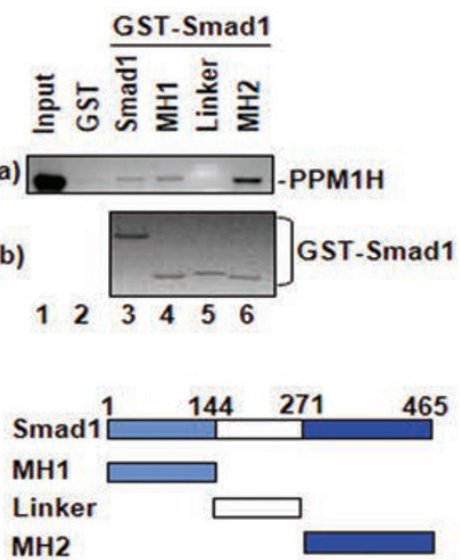

E

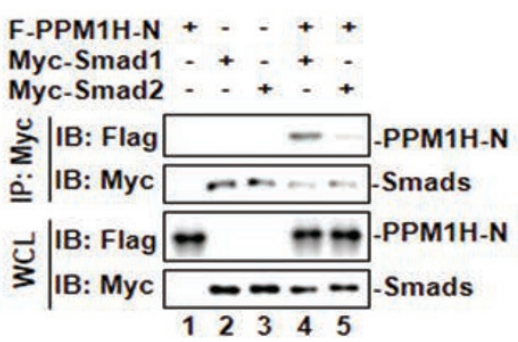

F

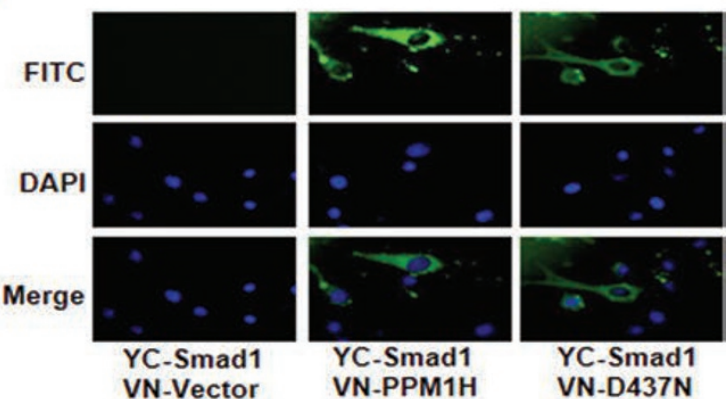

Figure 2 PPM1H physically interacts with Smad1. (A) PPM1H co-immunoprecipitates with Smad1. C2C12 cells stably expressing Myc-PPM1H were subjected to immunoprecipitation (IP) [27] with anti-Myc antibody, and PPM1H-bound endogenous Smad1 was detected by western blotting with anti-Smad1 antibody. Mouse IgG was used for control IP (lane 1). (B) PPM1H binds to Smad5 at endogenous levels. C2C12 cells were subjected to immunoprecipitation with anti-Smad5 antibody. Smad5-bound PPM1H was detected by western blotting with anti-PPM1H antibody. Rabbit lgG was used for control IP (lane 1). (C) The N-terminal region of PPM1H is the Smad1-binding domain. HEK293T cells were transfected with Myc-Smad1 and Flag-PPM1H or its mutants as follows: Flag- $\mathrm{N}$, N-terminal region of PPM1H; Flag-C, C-terminal region of PPM1H containing the catalytic domain of PPM1H; Flag-D437N. Interaction between Smad1 and PPM1H or its mutants was determined as described in A except that anti-Flag antibody was used for IP and anti-Myc antibody was used to detect PPM1H-interacting Smad1. (D) The MH2 domain of Smad1 interacts strongly with PPM1H. In vitro translated, ${ }^{35}$ S-labeled Flag-PPM1H was incubated with GST fusion protein of Smad1 or its mutants. Smad1-bound PPM1H was retrieved by glutathione beads and visualized by autoradiography. $\mathrm{MH} 1$, linker, and $\mathrm{MH} 2$ of Smad1 are shown. (E) PPM1H does not interact with Smad2. HEK293T cells were transfected with Flag-PPM1H-N together with either Myc-Smad1 or Myc-Smad2. Interaction between PPM1H-N and Smad1 or Smad2 was examined as described in C. PPM1H co-immunoprecipitated with Smad1 (lane 4) but not Smad2 (lane 5). (F) PPM1H associates with cytoplasmic Smad1. C2C12 cells were transfected with VN-PPM1H fusion and YC-Smad1 fusion, and the interaction between PPM1H and Smad1 was indicated by the fluorescence of YFP. VN-vector was used as control. DAPI: for nucleus staining. 
As shown in Figure 3C, BMP2 treatment induced an increase of nuclear Smad1 in control cells (lane 8). However, this induction was attenuated in PPM1Hexpressing cells (lane 10), but not in D437N mutantexpressing cells (lane 12), suggesting that PPM1H reduced Smad1 nuclear accumulation.

We next investigated the effect of PPM1Hmediated Smad1 dephosphorylation on BMP-regulated transcriptional responses. We utilized a BMP-responsive luciferase reporter SBE-OC containing multiple copies of Smad1-binding elements [32] upstream of the minimal promoter region of osteocalcin gene [33]. BMP2 treatment led to increased SBE-OC luciferase reporter expression in $\mathrm{C} 2 \mathrm{C} 12$ cells (Figure 3D). Ectopic expression of PPM1H, but not of the phosphataseinactive D437N mutant, abolished this BMP2-induced reporter expression (Figure $3 \mathrm{D}$ ). In addition to the synthetic promoter, we also examined the effect of PPM1H on the endogenous promoter activity of BMP target genes. Id 1 is one of the immediate early BMP target genes, which encodes a helix-loop-helix (HLH) protein that can form heterodimers with members of the basic HLH family of transcription factors to inhibit the DNA binding and transcriptional activation of basic HLH proteins [34]. The effect of PPM1H on the activity of Id1 gene promoter was determined in $\mathrm{C} 2 \mathrm{C} 12$ cells. We found that transient expression of $\mathrm{PPM} 1 \mathrm{H}$ attenuated the BMP-induced Id1 promoter activity (Figure 3E), while the two deletion mutants exhibited little (PPM1H-N) or no effect (PPM1H-C) (data not shown). Interestingly, the phosphatase-inactive D437N behaved like a dominantnegative mutant thereby stimulating the Id 1 promoter activity (data not shown). Similar inhibition by PPM1H was also observed with other BMP target genes such as p21 and osteoprotegerin (OPG) (Figure 3E). To prove that the inhibition of BMP target genes by PPM1H is through Smad1 dephosphorylation, we generated Smad1 SD and SE mutants in which the C-terminal serine residues in the SXS motif (Ser-463 and Ser-465) were replaced with Asp or Glu (designated SD and SE mutants, respectively). As a result, Smad1 SD and SE mutants function as the constitutively active forms of Smad1. As shown in Figure 3F, Smad1 co-expression induced Id1-Luc transcription activity, which was inhibited by co-expression of PPM1H. In contrast, the Smad1 SD or SE mutant-induced Id1-Luc activity was resistant to the co-expression of $\mathrm{PPM} 1 \mathrm{H}$, indicating that dephosphorylation of Smad1 mediates PPM1H inhibition of BMP target gene transcription.

\section{Knockdown of PPM1H expression induces hyperactive $B M P$ responses}

The data above have demonstrated that ectopic expression of PPM1H decreases Smad1 phosphorylation, Smad1 complex formation with Smad4, Smad1 nuclear accumulation, and Smad1-mediated transcriptional responses. To further confirm the role of endogenous PPM1H in regulating Smad1 activity, we determined the effect of PPM1H depletion on Smad1 activity. A PPM1H sequence-specific small hairpin RNA (shPPM1H) was

Figure 3 PPM1H attenuates BMP signaling. (A) PPM1H inhibits the complex formation between Smad1 and Smad4. FlagSmad1 and Myc-Smad4 were co-transfected with PPM1H or D437N mutant into HEK293T cells. ALK3QD was transfected to induce the Smad1-Smad4 complex formation. Smad1 was immunoprecipitated by anti-Flag antibody, and Smad1bound Smad4 was detected by western blotting with anti-Myc antibody. (B) PPM1H decreases endogenous Smad1-Smad4 interaction in $\mathrm{C} 2 \mathrm{C} 12$ cells. C2C12 control and PPM1H-WT stable cells were treated with BMP2 (5 ng/ml) for $2 \mathrm{~h}$. Cells were lysed and immunoprecipitation of endogenous Smad1 was performed using anti-Smad1 antibody to pulldown Smad1 and Smad1-bound Smad4. Rabbit IgG was used as negative IP control. (C) PPM1H inhibits BMP2-induced nuclear accumulation of Smad1. C2C12 cells stably expressing vector control, PPM1H, or D437N were treated with BMP2 (5 ng/ml), collected for cytoplasmic and nuclear fractions, and the subcellular location of Smad1 was determined by western blotting. Lamin A/C, nuclear protein marker; GAPDH, cytoplasmic protein marker. (D) PPM1H inhibits BMP2-induced SBE-OC-Luc reporter activity. C2C12 cells were transfected with SBE-OC-Luc reporter plasmid together with PPM1H or D437N, and cell lysates were collected for luciferase assay. (E) PPM1H inhibits BMP2-induced reporter activity of BMP2 target gene promoters. Expression of BMP2-induced Id1, p21, or OPG genes as indicated by natural promoter-driven luciferase reporter activity was determined in control and PPM1H transfected cells. (F) PPM1H inhibits Smad1-dependent transcriptional activation through Smad1 dephosphorylation. $\mathrm{C} 2 \mathrm{C} 12$ cells were transfected with Id1-Luc reporter plasmid and PPM1H together with the indicated plasmids: Smad1 WT, SD, or SE. SD and SE are phospho-mimicking and constitutively active mutants of Smad1. Luciferase activity was measured in cell lysates. (G) Knockdown of PPM1H increases the level of Smad1 phosphorylation in response to BMP2. Lysates from C2C12 cells stably expressing shPPM1H or control shRNA were used for western blotting with the indicated antibodies. BMP2 $(25 \mathrm{ng} / \mathrm{ml})$ treatment was done for $1 \mathrm{~h}$. $(\mathbf{H})$ shPPM1H markedly enhanced expression of $/ d 1$ in C2C12 cells, as assessed by qPCR. BMP treatment, RNA extraction, and qPCR data analysis were as described in "Materials and Methods". (I) shPPM1H markedly enhanced expression of Id1 in mouse ES cells. Experiments were done as described in $\mathbf{H}$. 
A

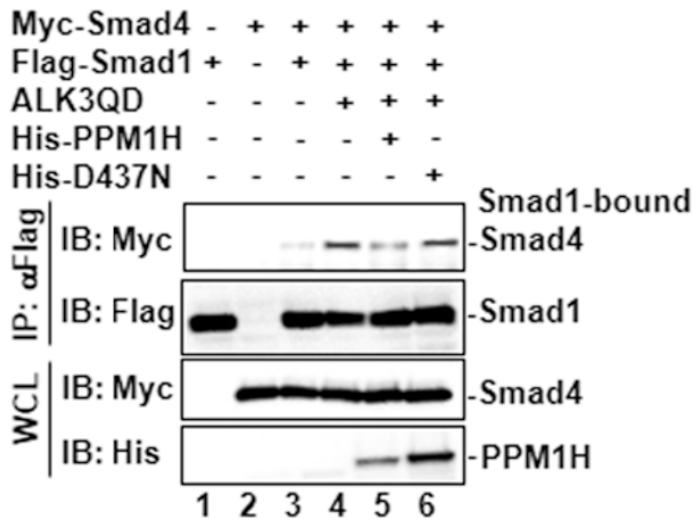

B

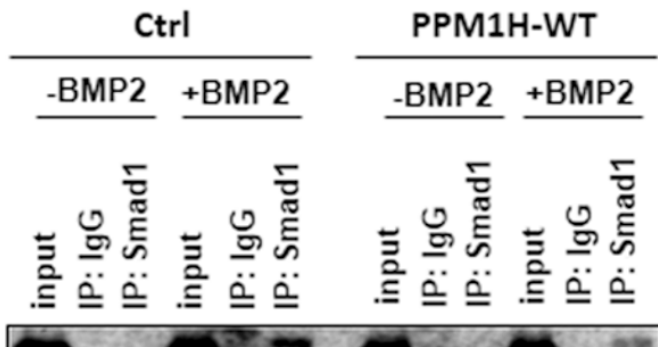

Smad1-bound Smad4

Smad1
C
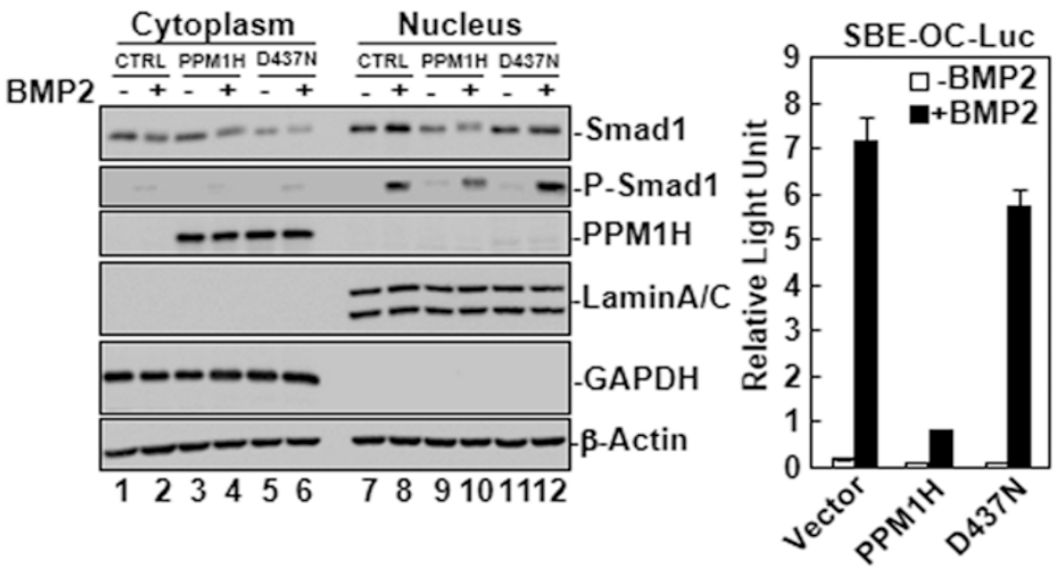

D E
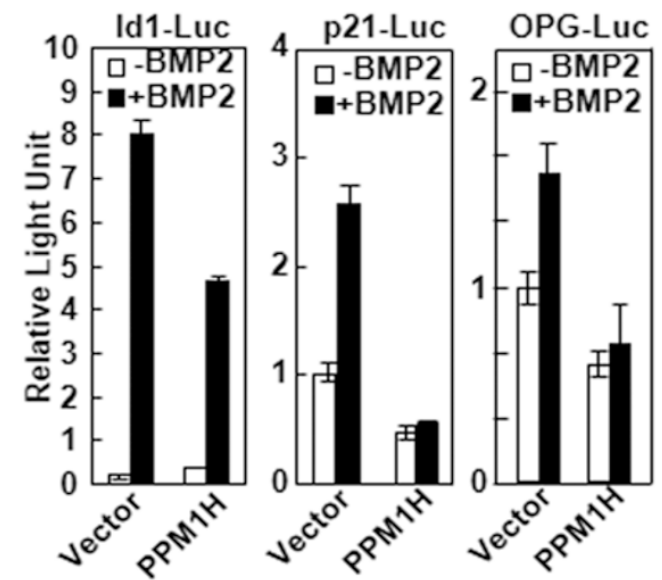

$\mathbf{F}$

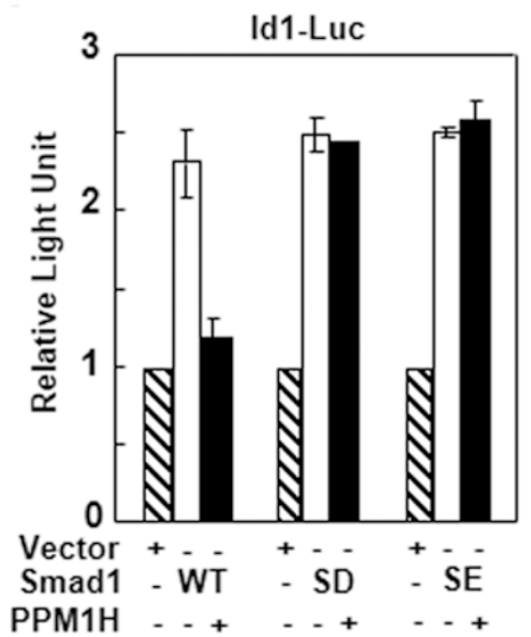

G

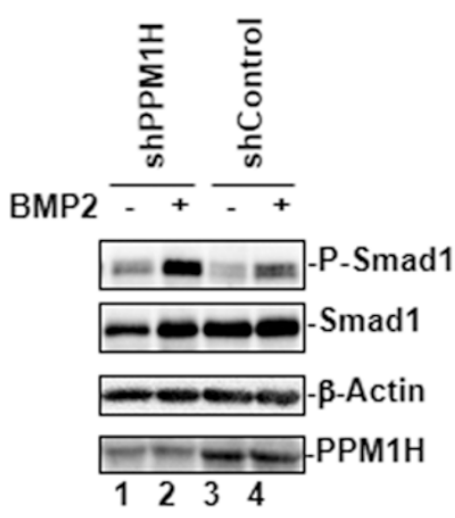

$\mathrm{H}$

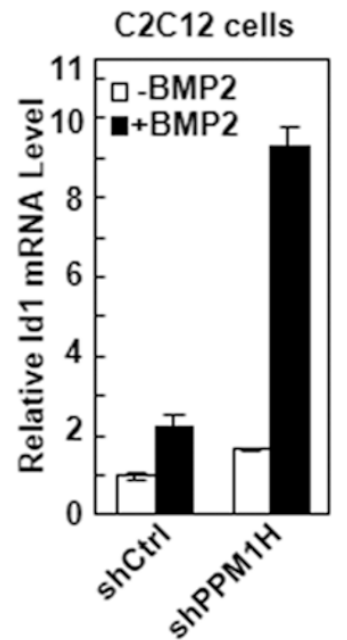

I

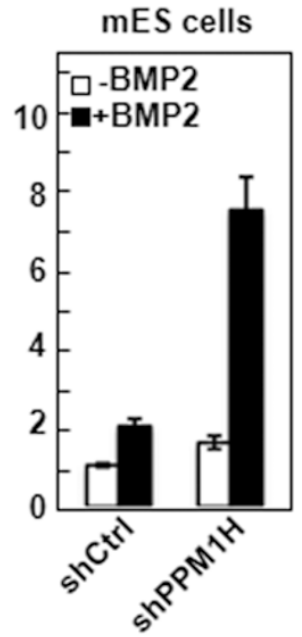


selected and tested for its effectiveness of knocking down PPM1H expression (Figure 3G, lanes 1 and 2). C2C12 cells stably expressing shPPM1H were then established to analyze the function of endogenous PPM1H in BMP signaling. We found that the BMP-induced Smad1 phosphorylation was enhanced in $\mathrm{C} 2 \mathrm{C} 12$-shPPM1H cells (Figure 3G, lane 2). As a result, shPPM1H strongly enhanced the transactivation of BMP target genes as measured by luciferase reporter activity of SBE-OCLuc and Id1-Luc (data not shown). Accordingly, the BMP2-induced endogenous Id1 mRNA transcription, as measured by qPCR, was markedly increased in shPPM1H-expressing $\mathrm{C} 2 \mathrm{C} 12$ cells (Figure $3 \mathrm{H}$ ) and mouse ES cells (Figure 3I). Thus, depletion of PPM1H expression induced hyperactive BMP responses in cells.

\section{PPM1H inhibits BMP-induced C2C12 osteoblast-like dif- ferentiation}

BMP has previously been reported to play an important role in osteoblast differentiation from progenitor cells [4]. To further investigate the physiological function of PPM1H by regulating Smad1 phosphorylation, we examined the effect of PPM1H on the osteoblastlike differentiation of $\mathrm{C} 2 \mathrm{C} 12$ cells. $\mathrm{C} 2 \mathrm{C} 12$ cells are mesenchymal progenitor cells that exhibit BMPinduced osteoblast-like differentiation, as indicated by the expression of osteoblastic marker genes, such as alkaline phosphatase (ALP) [35], Runx2, [36] and osterix (OSX) [37]. As shown in Figure 4A, BMP2 profoundly induced the expression of ALP in $\mathrm{C} 2 \mathrm{C} 12$ cells after 36 $\mathrm{h}$ of stimulation. However, this BMP2-induced response was abolished in $\mathrm{C} 2 \mathrm{C} 12$ cells stably expressing PPM1H (Figure 4A). In contrast, the D437N mutant of PPM1H failed to inhibit BMP-induced ALP production (Figure 4B). BMP2-induced mRNA expression of osteoblast master regulator Runx2, as measured by $\mathrm{qPCR}$, was also attenuated by PPM1H expression (Figure 4C). Conversely, knockdown of PPM1H enhanced the BMPinduced ALP production (Figure 4D), and mRNA expression of Runx-2 (Figure 4E) and OSX (Figure 4F), indicating the inhibitory effect of PPM1H in BMP2induced osteoblastic differentiation.

\section{PPM1H promotes myogenic differentiation of $\mathrm{C} 2 \mathrm{C} 12$ cells}

BMPs inhibit myogenic differentiation of $\mathrm{C} 2 \mathrm{C} 12$ cells by inducing Id1 gene transcription, which in turn suppresses the activity of the MyoD family transcription factors, critical regulators of myogenesis [38-41]. In our study, we found that PPM1H negatively regulated BMP signaling and inhibited Id1 transcription. We speculated that PPM1H might promote myogenic differentiation of $\mathrm{C} 2 \mathrm{C} 12$ cells by inhibiting BMP signaling. To test our hypothesis, we first investigated the effect of ectopic expression of PPM1H on the myogenesis of $\mathrm{C} 2 \mathrm{C} 12$ by using control $\mathrm{C} 2 \mathrm{C} 12$ cells, or $\mathrm{C} 2 \mathrm{C} 12$ cells stably expressing wild-type PPM1H or D437N mutant. Cells were subjected to differentiation medium $(2 \%$ horse serum) for 6 days to induce myogenesis. As shown in Figure 5A, expression of myosin heavy chain (MHC), a marker of myogenic differentiation, was enhanced more markedly in PPM1H-expressing $\mathrm{C} 2 \mathrm{C} 12$ cells than in control or in $\mathrm{D} 437 \mathrm{~N}$ mutant-expressing cells. Addition of BMP2 inhibited the expression of MHC (Figure 5B, lane 2), however, this BMP2-induced inhibitory effect was partially rescued by the expression of PPM1H (Figure 5B, lane 4), but not the D437N mutant. The effect of PPM1H on myogenesis was also investigated in $10 \mathrm{~T} 1 / 2$ pluripotent cells. Serum deprivation induced myogenic differentiation in 10T1/2 cells, as indicated by the induction of MyoD and myogenin gene expression (Figure 5C, lanes 2-6). This induction was further enhanced by the ectopic expression of PPM1H (Figure $5 \mathrm{C}$, lanes 8-12). Addition of BMP2 in the differentiation medium attenuated the induction of MyoD and myogenin gene expression (Figure 5D, lanes 3-6). This BMP2mediated inhibition, however, was blocked by PPM1H overexpression (Figure 5D, lanes 8-12). In support of these data, we observed that knockdown of PPM1H suppressed the expression of myogenic differentiation markers, as the mRNA levels of MHC (Figure 5E) and myogenin (Figure 5F) were strongly reduced in shPPM1H-expressing C2C12 cells. Immunofluorescence staining of $\mathrm{MHC}$ (an indicator for myotube formation) further demonstrated that knocking down PPM1H had an inhibitory effect on myogenic differentiation of $\mathrm{C} 2 \mathrm{C} 12$ cells (Figure 5G). However, treatment of shPPM1Hexpressing cells with dorsomorphin (DM) [42], a BMP type I receptor-specific inhibitor, increased myotube formation (Figure 5G), indicating that PPM1H promotes myogenic differentiation by inhibiting BMP signaling.

\section{Discussion}

In response to specific ligands, $\mathrm{R}-\mathrm{Smads}$ associate with the respective type I receptors and are phosphorylated at the C-terminal SXS motif by the associated type I receptors. In BMP signaling pathway, BMP type I receptors, ALK1/2/3/6 phosphorylates Smad1/5/8 following specific activation by BMPs [20, 43, 44]. Phosphorylated Smad1/5/8 forms a hetero-oligomeric complex with Smad4, and this complex accumulates in the nucleus to regulate gene transcription in conjunction with a variety of transcriptional cofactors [20, 43, 45]. Thus, R-Smad C-terminal SXS phosphorylation is the key step in acti- 
A
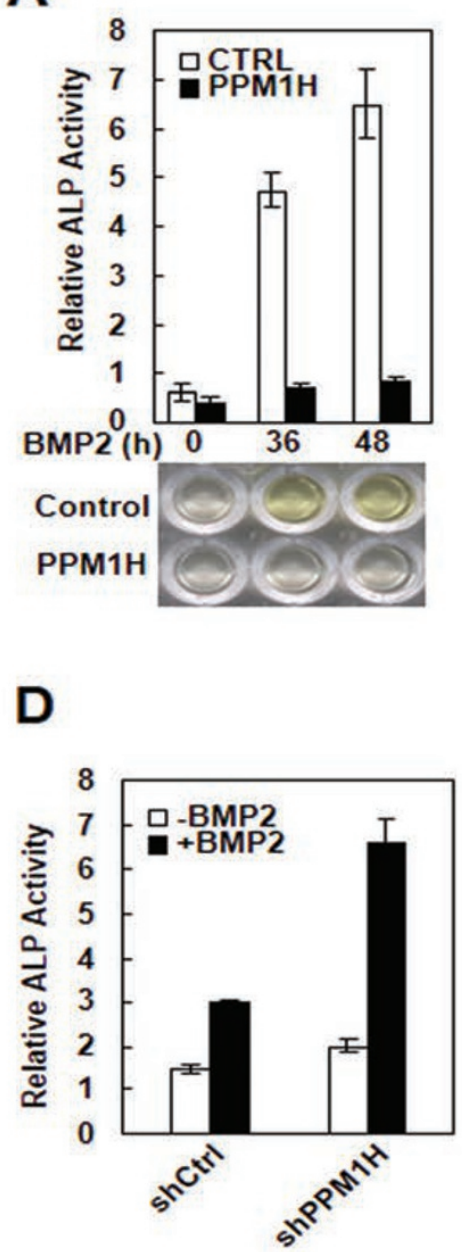

B

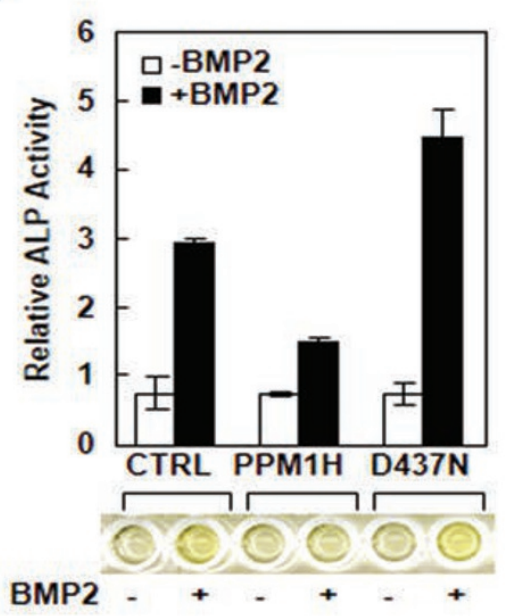

E

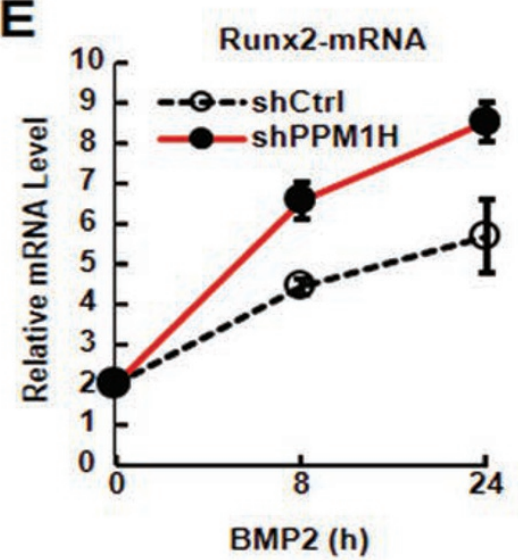

C

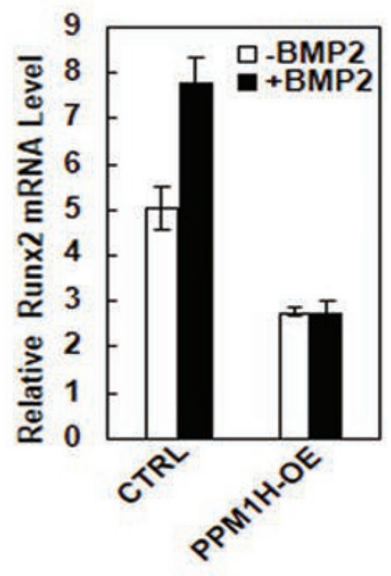

$\mathbf{F}$

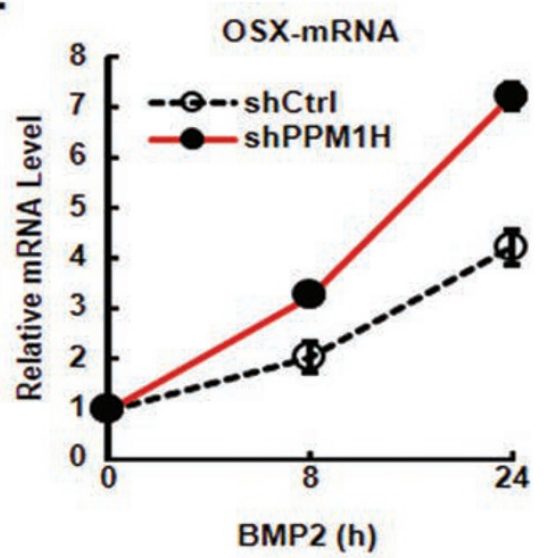

Figure 4 PPM1H inhibits BMP-induced osteoblast-like differentiation in C2C12. (A) Ectopic expression of PPM1H abolishes BMP2-induced ALP expression. C2C12 cells stably expressing PPM1H or control vector were treated with BMP2 (5 ng/ml) for $36 \mathrm{~h}$ or $48 \mathrm{~h}$, and their ALP levels were measured. (B) PPM1H, but not D437N mutant, inhibits BMP2-induced ALP expression. $\mathrm{C} 2 \mathrm{C} 12$ cells were transfected with wild-type PPM1H or D437N mutant. Twenty-four hours after transfection, cells were treated with BMP2 $(5 \mathrm{ng} / \mathrm{ml})$ for $24 \mathrm{~h}$ and lysed for ALP assay. (C) Ectopic expression of PPM1H inhibits BMP-induced Runx2 mRNA transcription. C2C12 cells stably expressing PPM1H or control vector were treated with BMP2 (5 ng/ml) for $24 \mathrm{~h}$. Runx2 mRNA level was analyzed by qPCR. (D) Knockdown of PPM1H enhances BMP-induced ALP expression. C2C12 cells stably expressing shPPM1H or control shRNA were treated with BMP2 $(5 \mathrm{ng} / \mathrm{ml})$ for $48 \mathrm{~h}$, and cell lysates were collected for ALP assay. (E) Knockdown of PPM1H increases BMP-induced Runx2 mRNA expression. C2C12 cells stably expressing shPPM1H or control shRNA were treated with BMP2 $(5 \mathrm{ng} / \mathrm{ml})$ for $8 \mathrm{~h}$, or $24 \mathrm{~h}$. mRNA level was analyzed by qPCR. (F) Knockdown of PPM1H increases BMP-induced OSX mRNA expression. Experiments were done as described in E.

vating Smad-mediated transcription.

Recent studies support the notion that dephosphorylation of R-Smads in the nucleus and their subsequent nuclear export act as critical regulatory mechanisms to terminate Smad signaling [22]. PPM1A, which appears to be the only nuclear phosphatase against the $\operatorname{Smad} 2 / 3$ SXS motif identified thus far [23], also dephosphorylates the SXS motif of P-Smad1/5/8 [24]. In addition, $\mathrm{SCP} 1 / 2 / 3$ has been reported to dephosphorylate P-Smad1 at the SXS motif [26] as well as all R-Smads in the linker region $[46,47]$. Because PPM1A and SCPs are nuclear phosphatases, they fit well in the model in which nuclear phosphatases critically dephosphorylate Smads and terminate transcriptional activities of Smads. Intriguingly, endosomal MTMR-4 [25] and mitochondrial phosphatase PDP [27] were also reported to dephosphorylate P-Mad/ Smad1. How PDP dephosphorylates P-Smad1 inside or outside of the mitochondria remains to be further investi- 
A



B



D $2 \% \frac{\text { CTRL }}{+++++++++++}$

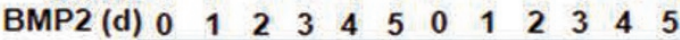
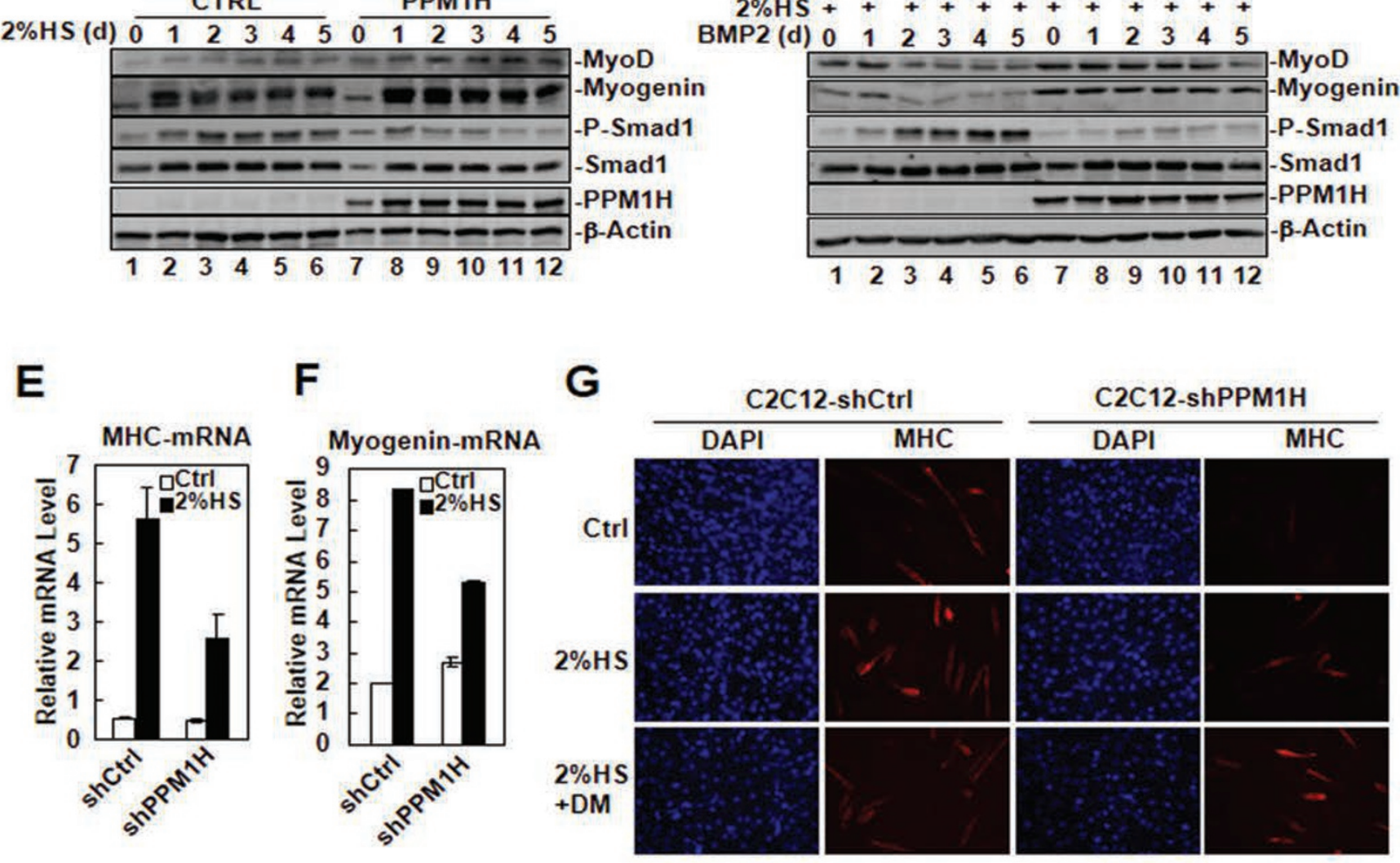

H

Smad1/5/8

BMP || PPM1H

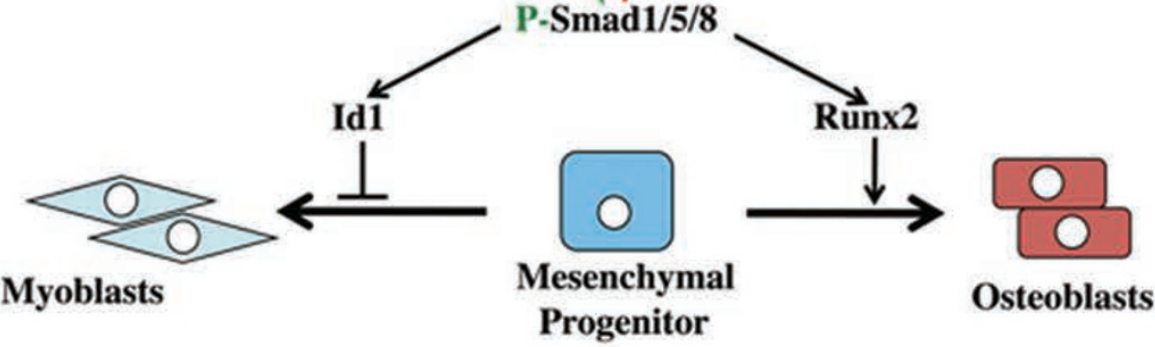


gated. In principle, despite phosphorylated Smads being short-lived in the cytoplasm, it stands to reason that they can also be dephosphorylated before their nuclear entry. Such dephosphorylation in the cytoplasm presumably serves as a "gatekeeper" mechanism to prevent Smad signaling.

In this study, we report the identification of a cytoplasmic phosphatase named PPM1H targeting Smad1 for dephosphorylation. Like PPM1A, PPM1H belongs to the PPM (protein phosphatase metal-ion-dependent) subfamily. But unlike PPM1A, PPM1H exhibits properties of substrate specificity and subcellular localization that are distinct from those of PPM1A. Whilst PPM1A is capable of dephosphorylating all R-Smads [23, 24], PPM1H specifically targets Smad1, and likely Smad5/8, in the BMP pathway. Overexpression of PPM1H leads to a reduced level of endogenous or exogenous P-Smad1 and subsequent Smad1-Smad4 complex formation, and this effect depends on the phosphatase activity of PPM1H. Furthermore, purified recombinant PPM1H can directly dephosphorylate P-Smad1 in vitro. This dephosphorylating activity is specific towards Smad1 C-terminal phosphorylation since PPM1H has no effect on Smad1 linker and Smad2/3 in the TGF- $\beta$ pathway. These results suggest that PPM1H is a Smad-specific phosphatase in the BMP pathway.

Another notable feature of PPM1H is its localization in the cytoplasm. This cytoplasmic localization distinguishes it from PPM1A, which is primarily located in the nucleus $[23,24]$. We previously reported that
PPM1A dephosphorylates R-Smads in the nucleus and facilitates their nuclear export, thereby terminating nuclear functions of Smads [23, 24, 48]. On the other hand, the cytoplasmic localization must keep PPM1H functioning in the cytoplasm. Indeed, we found that PPM1H physically interacts with Smad1 only in the cytoplasm and reduced the level of cytoplasmic phosphorylated Smad1. This "gatekeeper" function of PPM1H prevents Smad1-Smad4 complex formation and Smad1 nuclear accumulation. As a result, PPM1H inhibits BMP-mediated transcriptional responses. Conversely, depletion of endogenous PPM1H sensitizes the cells hyperactive to BMP responses. Functionally, PPM1H regulates mesenchymal cell differentiation by inhibiting the osteogenic response and promoting myogenic differentiation (Figure $5 \mathrm{H}$ ).

Expression of PPM1H is largely ubiquitous in mouse tissues (data not shown) and healthy human tissues (GeneCards: http://www.genecards.org/cgi-bin/carddisp. pl?gene=PPM1H\&search=PPM1H). Although PPM1H has been implicated in the regulation of neuronal signaling pathway [28] and perhaps in tumorigenesis, its substrates are mostly unknown. In the case of colon adenocarcinoma, PPM1H associates with, and may potentially dephosphorylate, CSE1L, a proliferationand apoptosis-related protein [29]. In the breast cancer, PPM1H may dephosphorylate tumor suppressor p27 and prevent p27 from proteasomal degradation [30]. Here we provide for the first time compelling evidence for a novel physiological role of PPM1H in controlling

Figure 5 PPM1H promotes myogenic differentiation. (A) Ectopic expression of PPM1H enhances MHC protein level during C2C12 myogenesis. C2C12 cells stably expressing PPM1H, D437N mutant or harboring control vector were cultured in differentiation medium ( $2 \%$ horse serum/DMEM) to induce myogenic differentiation. On day 6 , cell lysates were collected for western blotting with the indicated antibodies. (B) Ectopic expression of PPM1H partially rescues BMP2-mediated inhibition of $\mathrm{MHC}$ expression during $\mathrm{C} 2 \mathrm{C} 12$ myogenesis. $\mathrm{C} 2 \mathrm{C} 12$ cells stably expressing $\mathrm{PPM} 1 \mathrm{H}, \mathrm{D} 437 \mathrm{~N}$ mutant, or harboring control vector were cultured in differentiation medium. A subset of cells was treated with BMP2 (5 ng/ml) at the same time. MHC expression was determined by western blotting. (C) Ectopic expression of PPM1H enhances the induction of myogenic differentiation markers in 10T1/2 cells. 10T1/2 cells stably expressing PPM1H or carring control vector were cultured in differentiation medium. Cell lysates were collected and analyzed by western blotting with the indicated antibodies. Myogenin and myoD are myogenic markers. (D) Ectopic expression of PPM1H rescues BMP2 inhibition of myogenesis in 10T1/2 cells. $10 \mathrm{~T} 1 / 2$ cells stably expressing PPM1H or carrying control vector were cultured in differentiation medium. A subset of cells was treated with BMP2 $(5 \mathrm{ng} / \mathrm{ml})$ for the indicated days. Cell lysates were collected and analyzed by western blotting with the indicated antibodies. (E) Knockdown of PPM1H inhibits the mRNA transcription of myogenic marker gene MHC. C2C12 cells stably expressing shCtrl or shPPM1H were cultured in differentiation medium. Cell lysates were collected, and total RNA was prepared for subsequent qPCR analysis. (F) Knockdown of PPM1H inhibits the mRNA transcription of myogenic transcription factor myogenin. Experiment was done as in E. (G) Knockdown of PPM1H inhibits myotube formation. C2C12 cells stably expressing shCtrl or shPPM1H were cultured in differentiation medium in the presence or absence of DM for 4 days. Cells were fixed and immune-stained with anti-MHC antibody to abserve myotube formation under microscope. $(\mathrm{H})$ Schematic diagram for PPM1H-mediated dephosphorylation of Smad1/5/8 during mesenchymal differentiation. BMP-induced phosphorylation of Smad1/5/8 drives transcription of Runx2 (master transcription factor for osteoblast differentiation) and Id1 (inhibitor of differentiation for HLH transcription factors). PPM1H dephosphorylates P-Smad1/5/8 and consequently prevents osteoblast differentiation and enhances myoblast differentiation. 
BMP signaling through dephosphorylation of Smad1 (and likely Smad5/8) at the critical SXS motif. Our studies demonstrate that Smad1 is a bona fide substrate of $\mathrm{PPM} 1 \mathrm{H}$, and that $\mathrm{PPM} 1 \mathrm{H}$ negatively regulates BMPmediated osteoblast differentiation. Moreover, we also found that PPM1H can be moderately upregulated by BMP, forming a negative feedback loop (data not shown). Since Smad1 and Smad5 are also tumor suppressors in ovaries and testis [49], it is conceivable that the involvement of $\mathrm{PPM} 1 \mathrm{H}$ in neuronal functions and tumorigenesis may be partly mediated through its regulatory influences on Smad signaling. It will be clinically significant to elucidate the precise physiological mechanisms by which PPM1H controls the output of BMP-Smad signaling in cancer, skeletal, and neuronal disorders. PPM1H may also be a potential target for the prevention and intervention of these diseases.

\section{Materials and Methods}

\section{Plasmids}

Expression plasmids for epitope-tagged Smads were described previously $[50,51]$. PPM1H was obtained by RT-PCR and cloned into the EcoRI and SalI sites of pXF6F (a derivative of pRK5, Genentech). The D437N mutant (Asp to Asn substitution at aa 437) was constructed by two-step PCR, in which a fragment containing the mutation was amplified using a primer containing the mutation (sequence: 5'-GATCTTGGCCACTAATGGACTCTGGGA-3') and forward primer (5'-CGCGAATTCACCATGCTCACTCGAGTG AAATCTG-3'); this PCR product, together with reverse primer (5'-GGGGTCGACTCATGACAGCTTGTTTCCATGTA-3'), was then used as the primers to obtain the full-length PPM1H-D437N. The N-terminal deletion mutant of PPM1H was generated by PCR using forward primer 5'-CGCGAATTCACCATGCTCACTCGAG TGAAATCTG- $3^{\prime}$ and reverse primer $5^{\prime}$-AAGGTCGACTTAGGG CGTGTTCTCAGGCTCCT-3', and C-terminal deletion mutant by using forward primer $5^{\prime}$-AACGAATTCGCCAACAGCCGGACT CTGAC- 3 ' and reverse primer $5^{\prime}$-GGGGTCGACTCATGACAGC TTGTTTCCATGTA-3'. The mutants were also cloned into pXF6F.

The shRNA plasmids against mouse PPM1H: shmPPM1H 418 (target sequence GGCATCTCCTGCCACTACT) and shmPPM1H 866 (target sequence GGGCCATAATCATCAGAAA), were generated in pSRG vector [23].

\section{Antibodies}

Antibodies against P-Smad1, P-Smad2, and Myc epitope tag were purchased from Cell Signaling Technology. Smad1 and Smad2 antibodies were bought from Zymed and anti-PPM1H antibody from SDI. Antibodies against Flag and HA tags were purchased from Sigma, His tag from Serotec, and GFP from Invitrogen.

Cell culture, cell transfection, immunoprecipitation, and western blotting

Cell culture, transfection, immunoprecipitation, and western blotting were essentially performed as previously described $[23$,
24]. HEK293T and C2C12 cells were cultured in Dulbecco's modified Eagle's medium (DMEM) with 10\% fetal bovine serum (FBS). When indicated, cells were treated with $25 \mathrm{ng} / \mathrm{ml}$ of BMP2 in DMEM containing $0.2 \% \mathrm{FBS}$, for the indicated time, and then harvested for luciferase assay, immunoprecipitation, and western blotting.

\section{In vitro protein binding assay}

Recombinant GST fusion proteins were purified from E. coli as per manufacturer's instruction (Amersham Biosciences). In vitro-translated (TNT kit; Promega) ${ }^{35}$ S-labeled proteins were precleared with $5 \mu \mathrm{g}$ of GST protein first for $1 \mathrm{~h}$ and then incubated with $1 \mu \mathrm{g}$ of the indicated GST fusion proteins for $2 \mathrm{~h}$ in the in vitro binding buffer (50 mM Tris- $\mathrm{HCl}(\mathrm{pH} 7.5), 120 \mathrm{mM} \mathrm{NaCl}$, 2 mM EDTA, $0.1 \%$ NP-40), with the addition of protease/phosphatase inhibitor cocktail (Roche). After extensive wash with the in vitro binding buffer, proteins bound to GST fusion proteins were retrieved by glutathione sepharose beads (Amersham Pharmacia Biotech), separated by SDS-PAGE, and visualized by autoradiography.

\section{In vitro phosphatase assay}

P-Smad1 was immunoprecipitated by anti-P-Smad1 antibody from HEK293T cells transfected with Myc-Smad1 in the presence of ALK3QD. PPM1H was purified from bacteria as GST fusion protein. GST-PPM1H was incubated with P-Smad1 in the in vitro phosphatase buffer for $1 \mathrm{~h}$ at $37^{\circ} \mathrm{C}$. Dephosphorylation of Smad1 was analyzed by western blotting with anti-P-Smad1 antibody.

\section{Reporter assay}

Cells at 25\%-30\% confluency were co-transfected with expression plasmids for PPM1H and reporter plasmids indicated in the figure, and treated for $12 \mathrm{~h}$ with or without $25 \mathrm{ng} / \mathrm{ml} \mathrm{BMP}$. BMP2-induced transcription was analyzed by measuring luciferase activity as described previously [52].

\section{Immunofluorescence staining}

Cells grown on coverslips were fixed with $4 \%$ formaldehyde for $30 \mathrm{~min}$ at $4{ }^{\circ} \mathrm{C}$, permealized with $0.5 \%$ Triton X-100 for 30 min, and blocked with $5 \%$ milk in PEM buffer $(400 \mathrm{mM}$ potassium piperazine-N, N-bis(2-ethanesulfonic acid) (pH 6.8), $0.8 \mathrm{mM}$ EGTA, $5 \mathrm{mM} \mathrm{MgCl}$ ) at RT for $1 \mathrm{~h}$. Cells then were probed with the primary antibody indicated in the figure, followed by the fluorescence-conjugated secondary antibody in blocking buffer. After nuclear counterstaining by DAPI, cells were examined under Zeiss Axioplan II microscope.

\section{BiFC assay}

The assay was carried out as previously described [48]. VN (aa 1-155 fragment of Venus, a variant of YFP)-PPM1H and YC (aa 155-238 fragment of YFP)-Smad1 fusions were constructed in pcDNA3 expression vector, and expressed in cells by transfection. Fluorescence signal was examined under Zeiss Axioplan II microscope.

\section{ALP assay}

The ALP activity in cell lysates was determined by using $p$-nitrophenyl phosphate as a substrate (Sigma). 
$q P C R$

Total RNAs were prepared by TRIzol reagent (Invitrogen). RT-PCR was carried out with SYBR green (Applied Biosystems). Primers used for real-time PCR were as follows: PPM1H (forward, ACGGAGCAGATGACGTGCTGATC; reverse, T C GATAT C C G C C A C C C T C GG T C), Id 1 (forward, ACGACATGAACGGCTGCT; reverse, CA GCTGCA GGT C C C T GAT), Runx 2 (forward, G T TAT GAAAA A C CAA GTAGCCAGGT; reverse, G T A A T C T G A C T C T G T C C T T G T G G A T ), O S X ( forw ard, A G C G A C C A C T T G A G C A A A C A T; reverse, GCGGCTGATTGGCTTCTTCT), Myogenin (forward, C TA A A G T G G A G AT C C T G C G C A G C; reverse, GCAACA GACATAT C C T C CA C C G T G), MyoD (forward, ACTTTCTGGAGCCCTCCTGGCA; reverse, TTTGTTGCACTACACAGCATG) or MHC (forward, AGGGAGCTTGAAAACGAGGT; reverse, GCTTCCTCCAGCTCGTGCTG). mRNA levels were normalized against 18S RNA (forward, ATTGACGGAAGGGCACCACC; reverse, GCCAGAGTCTGTTCGTTATC). Each Sample was measured in triplicates. Data were analyzed using Microsoft Excel.

\section{C2C12 cell differentiation assay}

$\mathrm{C} 2 \mathrm{C} 12$ cells were cultured in $2 \%$ horse serum/DMEM for the indicated times to induce myogenic differentiation. C2C12 osteoblast-like differentiation was induced by BMP treatment $(25 \mathrm{ng} /$ $\mathrm{ml}$ ) for the indicated times.

\section{Acknowledgments}

We thank Dr Di Chen and Dr Peter ten Dijke for essential reagents. We are grateful to Ana María Rodríguez for editing of the manuscript. This research was supported by grants from MOST (2012CB966600), NSFC (31090360), NIH (R01DK073932, R01AR053591, R01GM063773, and R01CA108454), DoD-BCRP Idea Award (W81XWH-08-1-0745), NSFZ (Z2110591), Project 985, and the Fundamental Research Funds for the Central Universities.

\section{References}

1 Urist MR. Bone: formation by autoinduction. Science 1965; 150:893-899.

2 Wozney JM, Rosen V, Celeste AJ, et al. Novel regulators of bone formation: molecular clones and activities. Science 1988; 242:1528-1534.

3 Kingsley DM. The TGF-beta superfamily: new members, new receptors, and new genetic tests of function in different organisms. Genes Dev 1994; 8:133-146.

4 Cohen MM Jr. Bone morphogenetic proteins with some comments on fibrodysplasia ossificans progressiva and NOGGIN. Am J Med Genet 2002; 109:87-92.

5 Soderberg SS, Karlsson G, Karlsson S. Complex and context dependent regulation of hematopoiesis by TGF-beta superfamily signaling. Ann NY Acad Sci 2009; 1176:55-69.

6 ten Dijke P. Bone morphogenetic protein signal transduction in bone. Curr Med Res Opin 2006; 22 Suppl 1:S7-S11.

7 Wan M, Cao X. BMP signaling in skeletal development. Bio- chem Biophys Res Commun 2005; 328:651-657.

8 Miyazono K, Maeda S, Imamura T. BMP receptor signaling: transcriptional targets, regulation of signals, and signaling cross-talk. Cytokine Growth Factor Rev 2005; 16:251-263.

9 Kishigami S, Mishina Y. BMP signaling and early embryonic patterning. Cytokine Growth Factor Rev 2005; 16:265-278.

10 Chen D, Zhao M, Mundy GR. Bone morphogenetic proteins. Growth Factors 2004; 22:233-241.

11 Hardwick JC, Kodach LL, Offerhaus GJ, van den Brink GR. Bone morphogenetic protein signalling in colorectal cancer. Nat Rev Cancer 2008; 8:806-812.

12 Bobik A. Transforming growth factor-betas and vascular disorders. Arterioscler Thromb Vasc Biol 2006; 26:1712-1720.

13 Lories RJ, Luyten FP. Bone morphogenetic protein signaling in joint homeostasis and disease. Cytokine Growth Factor Rev 2005; 16:287-298.

14 Senta H, Park H, Bergeron E, et al. Cell responses to bone morphogenetic proteins and peptides derived from them: biomedical applications and limitations. Cytokine Growth Factor Rev 2009; 20:213-222.

15 Maciel TT, Kempf H, Campos AH. Targeting bone morphogenetic protein signaling on renal and vascular diseases. Curr Opin Nephrol Hypertens 2010; 19:26-31.

16 Yanagita M. BMP modulators regulate the function of BMP during body patterning and disease progression. Biofactors 2009; 35:113-119.

17 Kodach LL, Bleuming SA, Musler AR, et al. The bone morphogenetic protein pathway is active in human colon adenomas and inactivated in colorectal cancer. Cancer 2008; 112:300-306.

18 Shi Y, Massague J. Mechanisms of TGF-beta signaling from cell membrane to the nucleus. Cell 2003; 113:685-700.

19 de Caestecker $M$. The transforming growth factor- $\beta$ superfamily of receptors. Cytokine Growth Factor Rev 2004; 15:1-11.

20 Feng XH, Derynck R. Specificity and versatility in tgf-beta signaling through Smads. Annu Rev Cell Dev Biol 2005; 21:659-693.

21 Korchynskyi O, ten Dijke P. Identification and functional characterization of distinct critically important bone morphogenetic protein-specific response elements in the Id1 promoter. J Biol Chem 2002; 277:4883-4891.

22 Wrighton KH, Lin X, Feng XH. Phospho-control of TGF-beta superfamily signaling. Cell Res 2009; 19:8-20.

23 Lin X, Duan X, Liang YY, et al. PPM1A functions as a Smad phosphatase to terminate TGFbeta signaling. Cell 2006; 125:915-928.

24 Duan X, Liang YY, Feng XH, Lin X. Protein serine/threonine phosphatase PPM1A dephosphorylates Smad1 in the bone morphogenetic protein signaling pathway. J Biol Chem 2006; 281:36526-36532.

$25 \mathrm{Yu}$ J, He X, Chen YG, et al. Myotubularin-related protein 4 (MTMR4) attenuates BMP/Dpp signaling by dephosphorylation of Smad proteins. J Biol Chem 2013; 288:79-88.

26 Knockaert M, Sapkota G, Alarcon C, Massague J, Brivanlou $\mathrm{AH}$. Unique players in the BMP pathway: small C-terminal domain phosphatases dephosphorylate Smad1 to attenuate BMP signaling. Proc Natl Acad Sci USA 2006; 103:1194011945.

27 Chen HB, Shen J, Ip YT, Xu L. Identification of phosphatases 
for Smad in the BMP/DPP pathway. Genes Dev 2006; 20:648653.

28 Labes M, Roder J, Roach A. A novel phosphatase regulating neurite extension on CNS inhibitors. Mol Cell Neurosci 1998; 12:29-47.

29 Sugiura T, Noguchi Y, Sakurai K, Hattori C. Protein phosphatase $1 \mathrm{H}$, overexpressed in colon adenocarcinoma, is associated with CSE1L. Cancer Biol Ther 2008; 7:285-292.

30 Lee-Hoeflich ST, Pham TQ, Dowbenko D, et al. PPM1H is a p27 phosphatase implicated in trastuzumab resistance. Cancer Discov 2011; 1:326-337.

$31 \mathrm{Hu}$ CD, Kerppola TK. Simultaneous visualization of multiple protein interactions in living cells using multicolor fluorescence complementation analysis. Nat Biotechnol 2003; 21:539-545.

32 Hofbauer LC, Dunstan CR, Spelsberg TC, Riggs BL, Khosla S. Osteoprotegerin production by human osteoblast lineage cells is stimulated by vitamin $\mathrm{D}$, bone morphogenetic protein-2, and cytokines. Biochem Biophys Res Commun 1998; 250:776781.

33 Zhao M, Qiao M, Harris SE, et al. Smurfl inhibits osteoblast differentiation and bone formation in vitro and in vivo. $J$ Biol Chem 2004; 279:12854-12859.

34 Norton JD. ID helix-loop-helix proteins in cell growth, differentiation and tumorigenesis. J Cell Sci 2000; 113 ( Pt 22):3897-3905.

35 Pittenger MF, Mackay AM, Beck SC, et al. Multilineage potential of adult human mesenchymal stem cells. Science 1999; 284:143-147.

36 Komori T. Regulation of osteoblast differentiation by Runx2. Adv Exp Med Biol 2010; 658:43-49.

37 Nakashima K, Zhou X, Kunkel G, et al. The novel zinc finger-containing transcription factor osterix is required for osteoblast differentiation and bone formation. Cell 2002; 108:17-29.

38 Benezra R, Davis RL, Lassar A, et al. Id: a negative regulator of helix-loop-helix DNA binding proteins. Control of terminal myogenic differentiation. Ann NY Acad Sci 1990; 599:1-11.

39 Tapscott SJ, Davis RL, Lassar AB, Weintraub H. MyoD: a regulatory gene of skeletal myogenesis. Adv Exp Med Biol 1990; 280:3-5; discussion 5-6.

40 Ludolph DC and Konieczny SF. Transcription factor families: muscling in on the myogenic program. FASEB $J$ 1995;
9:1595-1604.

41 Molkentin JD, Olson EN. Combinatorial control of muscle development by basic helix-loop-helix and MADS-box transcription factors. Proc Natl Acad Sci USA 1996; 93:93669373.

$42 \mathrm{Yu}$ J, He S, Friedman JS, et al. Altered expression of genes of the Bmp/Smad and Wnt/calcium signaling pathways in the cone-only Nrl-/- mouse retina, revealed by gene profiling using custom cDNA microarrays. J Biol Chem 2004; 279:42211-42220.

43 Schmierer B, Hill CS. TGFbeta-SMAD signal transduction: molecular specificity and functional flexibility. Nat Rev Mol Cell Biol 2007; 8:970-982.

44 Moustakas A, Heldin $\mathrm{CH}$. The regulation of TGFbeta signal transduction. Development 2009; 136:3699-3714.

45 Massague J, Seoane J, Wotton D. Smad transcription factors. Genes Dev 2005; 19:2783-2810.

46 Sapkota G, Knockaert M, Alarcon C, et al. Dephosphorylation of the linker regions of Smad1 and Smad2/3 by small Cterminal domain phosphatases has distinct outcomes for bone morphogenetic protein and transforming growth factor-beta pathways. J Biol Chem 2006; 281:40412-40419.

47 Wrighton KH, Willis D, Long J, et al. Small C-terminal domain phosphatases dephosphorylate the regulatory linker regions of Smad2 and Smad3 to enhance transforming growth factor-beta signaling. J Biol Chem 2006; 281:38365-38375.

48 Dai F, Lin X, Chang C, Feng XH. Nuclear export of Smad2 and Smad3 by RanBP3 facilitates termination of TGF-beta signaling. Dev Cell 2009; 16:345-357.

49 Pangas SA, Li X, Umans L, et al. Conditional deletion of Smad1 and Smad5 in somatic cells of male and female gonads leads to metastatic tumor development in mice. Mol Cell Biol 2008; 28:248-257.

50 Lin X, Liang M, Feng XH. Smurf2 is a ubiquitin E3 ligase mediating proteasome-dependent degradation of Smad 2 in transforming growth factor-beta signaling. J Biol Chem 2000; 275:36818-36822.

51 Lin X, Liang YY, Sun B, et al. Smad6 recruits transcription corepressor CtBP to repress bone morphogenetic proteininduced transcription. Mol Cell Biol 2003; 23:9081-9093.

52 Feng XH, Lin X, Derynck R. Smad2, Smad3 and Smad4 cooperate with $\mathrm{Sp} 1$ to induce p15(Ink4B) transcription in response to TGF-beta. EMBO J 2000; 19:5178-5193. 